International Journal of Health Sciences
Available online at www.sciencescholar.us
Vol. 5 No. 3, December 2021, pages: $331-343$
e-ISSN: 2550-696X, p-ISSN: $2550-6978$
https://doi.org/10.53730/ijhs.v5n3.1541

\title{
Correlation Between Levels of LGR-5 (Leucine Rich Repeat Containing Protein Coupled Receptor 5) with Clinical Aspects and Colorectal Carcinoma Stage
}

\begin{tabular}{l} 
Abstract \\
Manuscript submitted: 18 May 2021, Manuscript revised: 09 August 2021, Accepted for publication: 26 September 2021 \\
\hline This study analyzes colorectal cancer refers to gradually growing cancer that \\
begins as tumor or tissue development in the internal layer of the rectum or \\
stomach. CRC is resistant to chemotherapy and radiation and can cause \\
collapse. This study is an analytical observational study using a cross-sectional \\
study design with an evaluation stage of increasing LGR-5 levels on clinical \\
aspects and stages of Colorectal Carcinoma patients in Makassar. Data \\
collection was primary, where the data were taken was demographic data and \\
related to clinical aspects of the patient, namely, age, gender, cancer location, \\
and cancer stage, lymph node participation, histopathological type when the \\
patient came to treatment with a diagnosis of colorectal cancer. The non- \\
sanskari analysis was carried out on variables from the results of the study \\
using contradiction analysis to determine the relationship between the \\
increased level of LGR-5 and the stage of carcinogen ma patients based on AJCC. \\
The analysis was carried out with the chi-square test. The value of significance \\
is obtained when p <0.05. We can summarize the accepted results that there is \\
no significant relationship between LGR-5 levels on gender, age, and tumor \\
location in colorectal cancer patients, there is a significant relationship between \\
LGR-5 levels on cancer stage, degree of differentiation, and incidence of \\
metastases in cancer patients. colorectal.
\end{tabular}

International Journal of Health Sciences (C) 2021. This is an open access article under the CC BY-NC-ND license (https://creativecommons.org/licenses/by-nc-nd/4.0/).

\footnotetext{
a Department of Surgery, Faculty of Medicine, Hasanuddin University, Makassar, Indonesia

b Digestive Surgery Division, Department of Surgery, Hasanuddin University, Makassar, Indonesia

c Department of Public Health, Hasanuddin University, Makassar, Indonesia

d Digestive Surgery Division, Department of Surgery, Hasanuddin University, Makassar, Indonesia

e Digestive Surgery Division, Department of Surgery, Hasanuddin University, Makassar, Indonesia
} 


\begin{tabular}{|c|c|c|}
\hline \\
\hline \multicolumn{3}{|c|}{$\begin{array}{l}\text { Contents } \\
\text { Abstract.... }\end{array}$} \\
\hline 1 & Introduction .................................. & 332 \\
\hline 2 & Materials and Methods & 333 \\
\hline 3 & Results and Discussions & 334 \\
\hline 4 & Conclusion & 339 \\
\hline & Acknowledgments. & 339 \\
\hline & References & 340 \\
\hline & Biography of Authors & 342 \\
\hline
\end{tabular}

\section{Introduction}

Colorectal cancer refers to gradually growing cancers that develop into tumors or tissue rectum or internal layer of the stomach. If these abnormal growths, known as animals, eventually develop cancer, they will become tumors in the walls of the rectum or stomach, and then develop into blood vessels or lymph vessels, increasing the chances of metastasis in other physical sites (Ziskin et al., 2013). The term colorectal cancer (CRC) is based on the similarity of the anatomical structure consisting of the mucosa, muscle layer, and part of the serosa, its function in the formation of feces, fluid resorption, transportation, and excretion of feces, as well as histological similarities. The initial boundary is the ileocecal valve and the back boundary is the edge of the anus which is marked by a dental line to the canal, sphincter, and skin (Valastyan \& Weinberg, 2011).

As indicated by gauges from the International Agency for Research on Cancer, in 2018, around the world, colorectal disease represented roughly 1.8 million new cases and 900,000 passing every year, making it the third most as often as a possible analyzed threat and the subsequent driving reason for malignant growth demise. Like clockwork, the American Cancer Society gives reports on the occurrence of CRC dependent on episode information (accessible through 2016) from populace-based malignant growth libraries and mortality information (until 2017) from the National Centers for Health Statistics. (GLOBOCAN, 2018), In 2020, it is assessed that around 147,950 individuals will be determined to have TRC, and 53,200 will kick the bucket from the illness, remembering 17,930 cases and 3,640 passing for people under 50 years old (Siegel et al., 2020).

Fundamentally the pace of movement of CRC and mortality increments quickly after the age of 50, with an expected $90 \%$ of worldwide cases and passing happening after this age. Higher CRC rates in men might be identified with a mix of elements. Contrasted and ladies, men give off an impression of being more affected by ecological than hereditary variables in colorectal carcinogenesis, with CRC heritability assessed at $28 \%$ for men and 45\% for ladies (Rawla et al., 2018; Widana et al., 2021). CRC of care, including careful strategies, causes diverse crc endurance rates around the world, which is the resultant factor for neighborhood repeat and treatment rate. Colorectal malignancy that metastasized, or spread, has a helpless guess and a high danger of repeat in provincial lymph hubs. Studies show that within 2-5 years 15 to 30 percent of patients were determined to have hub negative colorectal malignant growth experience illness repeat (Fatemi et al., 2015).

Cancer stem cell (CSC) was first introduced by Hope KJ (1977), in a population of acute myeloid leukemia cells, and it is believed that cancer tissues have three cellular populations such as Samei tissue: stem cells, spread cells, and mature cells (Shekarriz et al., 2019). Many treatment protocols have been applied to crc, but may not have occurred in a full treatment, which may be due to stem cells. CRC is resistant to chemotherapy and radiation and can cause collapse. Cancer stem cell (CSC) or cancer stem cell is a group of tumor cells that have the potential to have characteristics of self-renewal stem cells, unrestricted spread, and multidirectional discrimination. CSC comprises a tiny populace of malignant growth, yet is firmly connected with cancer metastasis, drug opposition, and repeat after medical aid. All around treated strange flagging pathways in colorectal CSCs including Wnt/ $\beta$-catenin, Notch, TGF- $\beta$, and Hedgehog. WNT/ $\beta$-Catanine course is significant in the strength of colorectal CSC and upkeep of medication opposition (Wu et al., 2012).

5 Leucine-rich, repetitive, G Protein-Coupled (LGR-5) receptor containing Lucine containing G protein, also known as G protein-coupled receptor 49 (GPR49), an "orphan" receptor family g belongs to protein-coupled receptor (GPR). LGR-5 modifies the strength of the prescribed Wnt signal through binding for its R-Spondin Ligad. LGR-5 strengthens the WNT/ $\beta$-Catanine signaling pathway, thereby stimulating the spread and renewal 
of cancer stem cells. LGR-5 is shown to increase cancer cell mobility, tumor formation, and epithelialmesenchymal infection through Wnt/ $\beta$-catenin signaling activity (Nakata et al., 2014). The role of LGR-5 and its clinical implications have been reported in various studies, but the results of various studies leading to this topic are controversial. Excess levels of LGR-5 have been associated with recurrence, metastasis, and poor prognosis in CRC. In contrast, another study found no correlation with prognosis, concluding that LGR-5 levels were not associated with poor prognosis, as might be anticipated for CSC markers. Unfortunately, the LGR-5 CSC still plays a role (Dharmayuda et al., 2021; Carchi et al., 2021).

\section{Materials and Methods}

This research is an analytical observational study using a cross-sectional research design. This study will evaluate the increase in LGR-5 levels on clinical aspects (age, sex, tumor location) and patient stage (histological type, degree of histopathological differentiation, lymph node metastases, liver metastases) Colorectal Carcinoma in Makassar. The target population in this study were all patients with colorectal carcinoma who were registered at Wahidin Sudirohusodo General Hospital. The affordable population in this study were all patients with colorectal carcinoma who were registered at Wahidin Sudirohusodo General Hospital in 2021 until the sample was met (Barker \& Clevers, 2010; Fukuma et al., 2013).

The research sample is representative of the affordable population selected using the consecutive sampling method, namely the selection of samples by determining subjects who meet the research criteria to be included in the study for a certain period so that the number of respondents can be met. Determining the sample criteria is very helpful for research to reduce research bias, especially if there are variables (controls or confounders) that influence the variables studied. Sample criteria can be divided into two, namely inclusion and exclusion (Fukuma et al., 2013; Huang et al., 2016).

Data collection was carried out primary, where the data are taken were demographic data and related to clinical aspects of the patient, namely, age, gender, cancer location, and cancer stage, lymph node involvement, histopathological type when the patient came for treatment with a diagnosis of colorectal cancer. Then from the data obtained, LGR-5 levels were examined directly through immunohistochemistry examination at the Department of Anatomical Pathology, RSUP Dr. Wahidin Sudirohusodo. According to Notoatmodjo (2010), Data processing is carried out in the following stages: Editing: checking the data that has been collected and checked for correctness. Coding: the questionnaire sheets are coded based on the answers given by the respondents, coding can be done before or after data collection. Transferring: compilation of data so that it is easy to add, organize and record data for presentation and analysis. Tabulating: moving the data obtained and arranged into a table (Kuipers et al., 2015; Bratt, 2002).

Univariate analysis was carried out on the variables from the research results. This analysis produces the distribution and presentation of each variable. Then after knowing the category for each variable, the researcher will calculate the frequency and find the percentage for each variable. In this study, the bivariate analysis will also be carried out to determine the relationship between increased levels of LGR-5 and the stage of rectal carcinoma patients based on AJCC. The analysis was carried out with the chi-square test (Rhee et al., 2017; Baena \& Salinas, 2015). The value of significance is obtained when $\mathrm{p}<0.05$. Statistical analysis was performed using SPSS 24.

Arungpadang, M. P., Lusikooy, R. E., Kasim, F., Mappincara, M., \& Warsinggih, W. (2021). Correlation between

levels of LGR-5 (leucine rich repeat containing protein coupled receptor 5) with clinical aspects and colorectal carcinoma stage. International Journal of Health Sciences, 5(3), 331-343. https://doi.org/10.53730/ijhs.v5n3.1541 


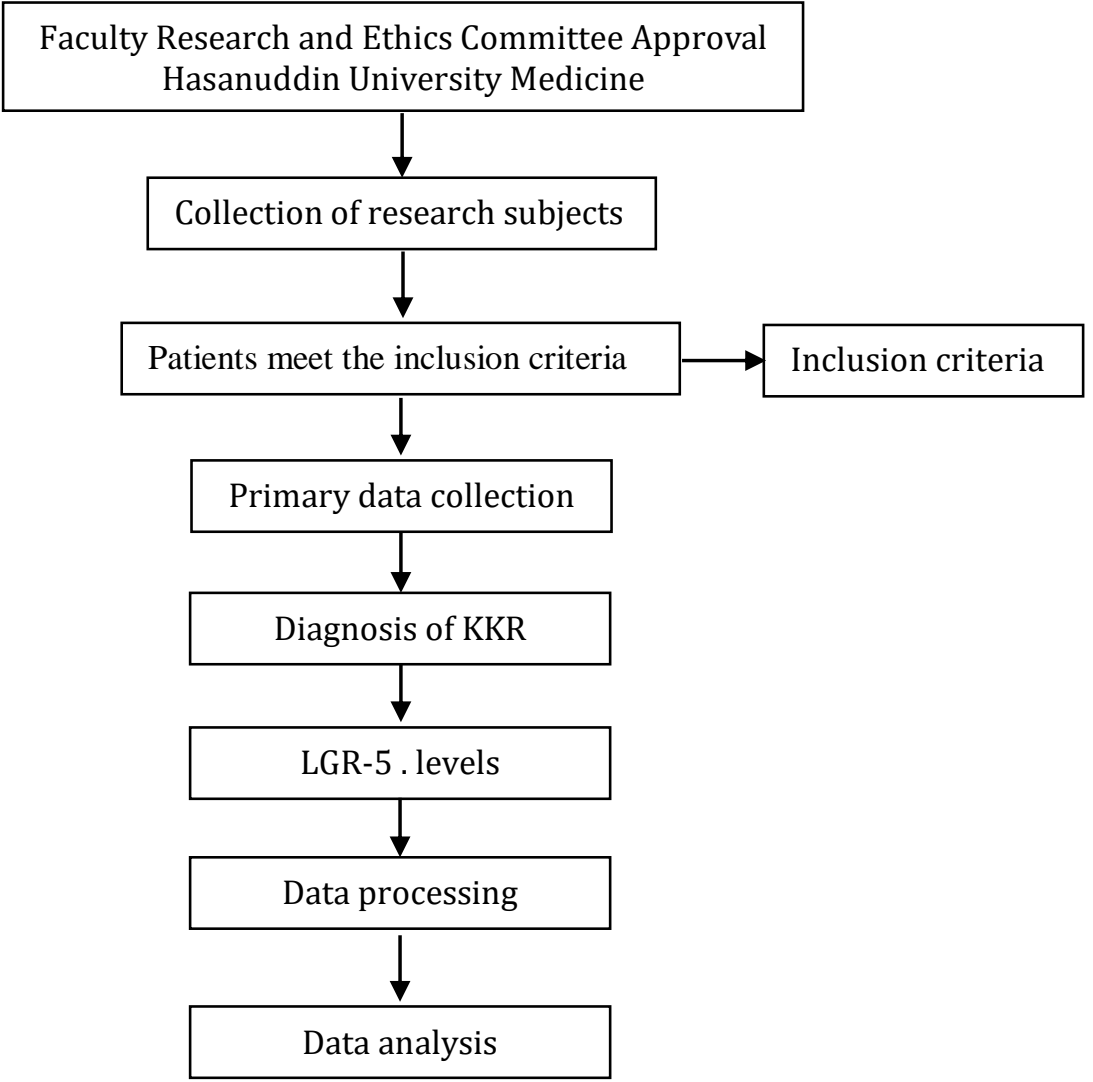

Figure 1. Research flow

\section{Results and Discussions}

In this study, the distribution of demographic, clinical, and staging data for colorectal cancer can be summarized from a table that describes the distribution based on sex, age, chief complaint, tumor location, cancer stage, degree of differentiation, the incidence of metastases, and LGR-5 levels with a total sample of approx. 61 people (Winawer, 1999; Leushacke \& Barker, 2012).

\section{Age}

Most patients aged $>40$ years (73.8\%) in this study. These results are in line with the study report by Shekarriz et al. (2019), that the median age of colorectal cancer sufferers in Iran is 64 years, more than 40 years (Shekarriz et al., 2019). Ihemelandu et al. (2019), also reported that the median age of patients with colorectal cancer at Georgetown's MedStar University hospital was 61.4 years (Ihemelandu et al., 2019). Pathomechanisms of age that can cause colon carcinoma are thought to include mutations in the DNA of the cells that make up the colonic wall, which accumulates with increasing age and decrease in immune system function and the increased intake of carcinogenic agents. As with other malignancies, age is the dominant risk factor for CRC. The risk of CRC increases with age, especially in men and women aged 50 years, where 9 out of 10 people diagnosed with CRC are at least 50 years old (Beckmann et al., 2015).

In the United States, individuals beyond 65 three years old are multiple times bound to be determined to have CRC than those in the age gathering of 50-64 years, and multiple times bound to be analyzed than those in the age gathering of 25-49 years. While the frequency pace of the illness has diminished over the most recent couple of a long time among those more than 50 , the occurrence rate for those under 50 has expanded. 
Scientists accept that this can be an impression of a greater stable way of life and from that point forward it is prescribed to diminish screening under-the-age evaluating for 45 preceding recognizing cases in youthful grown-ups (Rawla et al., 2018). Based on this study, we suspect that the absence of an association between the age of CRC patients and the levels of CRC Stem Cells is the result of epigenetic changes associated with the aging process (Christensen et al., 2009). This research proves that LGR-5 levels are not related to the age of CRC sufferers.

\section{Gender}

In this study, a total of 61 samples of colorectal cancer patients with men being the most cases were 38 people (62.3\%) compared to 23 people (37.7\%) in women. This result is almost the same as the study report by Shekarriz et al. (2019), that of 40 patients with colorectal cancer (CRC) at the Imam Khomeini Sari hospital, Iran, there were more male patients (52.5\%) than women (47.5\%) (Shekarriz, et al., 2019). However, this result is different from the study report by Ihemelandu et al. (2019), on 49 TRC patients from the Medstar Georgetown University Hospital from 2009 to 2015 where there were more female sufferers, namely 30 (61\%) than men, namely 19 people ( $39 \%$ ) (Ihemelandu et al., 2019). Gender factors are also thought to be related to stem cell activity as reported in previous studies that Mesenchymal Stem Cells (MSCs) of female rhesus monkeys aged 2 years have a greater neurogenic capacity than male monkeys (Yuan et al., 2010).

In all ages and countries, men are 1.5 times more likely to be diagnosed with colorectal cancer than women. Among older adults in the United States, gender differences have declined in recent decades to reflect gender differences between young sexes. Compared to men, women are at a higher risk of right-sided colorectal cancer, which is more aggressively linked to neoplasia than left-sided colorectal cancer. Women over the age of 70 have a 5-year survival rate compared to men (Rawla et al., 2018). In patients with CRC, there are more men than women because of differences in hormone levels, daily activities, and food consumption which are considered as risk factors for CRC. In addition, other factors, such as smoking in the long term, increase the risk of adenoma turning into CRC (Bollati \& Baccarelli, 2010). In this study, it was shown that changes in levels/expressions in TRC Cancer Stem Cells were related to various factors that influence cancer development, such as sex hormones, genetic differences, and epigenetics. Environmental factors, lifestyle also affect the epigenome (Bollati \& Baccarelli, 2010). This is in line with this study which proves that LGR-5 levels are not related to gender in TRC patients.

\section{Tumor location}

In this review, the most famous cancer area is sigmoid colon $27.9 \%(17 / 61), 23 \%(14 / 61)$, colon swells crossed more than $21.3 \%$ (13/61), rising colon 14.8\% (9/61). 61), Colon 13.1\% (8/61). A concentrate by Zheng et al (2018) tracked down that colorectal disease (CRC) is all the more ordinarily found in the left midregion (cross over colon, sliding colon, sigmoid colon, and rectum) than 146 (ileocium colon, climbing colon) contrasted with 58 found in the right midsection. And hepatic flexors of the transverse colon) (Zheng et al., 2018).

The results of this study are in line with those conducted at the Tehran University of Medical Science Hospital, it was found that from 218 patients suffering from colorectal cancer, 126 predilections were found in the rectum, followed by the sigmoid colon in 38 cases. Not explained specifically the reason why the location of colorectal malignancies is more common in the rectum, it is associated with several risk factors. The colon and rectum have different functions, the colon functions as absorption of food waste substances while the rectum has functioned as a storage place for feces before being expelled through the anus, those undigested substances through the colon are lined with alkaline mucus (Thoresen et al., 2013; Heinen, 2010).

Two-thirds of crc is in the left stomach and one-third is in the right stomach. However, over the past few decades, crc was considered a disease with the primacy of space in the left stomach or distal colon. Over the past 20 years, data from epidemiological studies show that the proportion of left to right tumor locations has increased. In North America and Europe, there has been an increase in the incidence of tumor sites in the right and adjacent stomach. The same trend is seen in Asian countries. The change in the left to right tumor location is considered multifunctional, including (i) increase in life expectancy in the community, the presence of various variations in response to procarcinogen and intraluminal carcinogens at various sites between (ii)

Arungpadang, M. P., Lusikooy, R. E., Kasim, F., Mappincara, M., \& Warsinggih, W. (2021). Correlation between levels of LGR-5 (leucine rich repeat containing protein coupled receptor 5) with clinical aspects and colorectal carcinoma stage. International Journal of Health Sciences, 5(3), 331-343. https://doi.org/10.53730/ijhs.v5n3.1541 
colon and rectuminal carcinogens, and (iii) the role of these factors. Genetic factors in MMR gene defects that cause MSI in adjacent stomach cancer, and sin passage which is prominent in left stomach and cancer (Graph 3) (Amori et al., 2017). Based on the results of the above study and the results of our study, it was shown that the level of LGR-5 was not associated with the location of the CRC tumor.

\section{Stadium}

Looking at the stage of colorectal cancer patients in this study, most were at stage $4(49.2 \%)$ and only one person was at stage $1(1.6 \%)$. This result is the same as that reported by Ihemelandu et al. (2019), in their study, colorectal cancer patients at MedStar Georgetown University Hospital were mostly at stage 4 (46.7\%) and the least at stage 1 (8.3\%) (Ihemelandu et al., 2019). While different results were reported by Wu et al. (2012), in their retrospective study that of 192 colorectal cancer patients from 2001 - 2004, most were in stage 2 (70 people), followed by stage 3 (65 people), then stage 1 ( 47 people) and at least at stage 4 (10 people) (Wu et al., 2012). In this study, it was found that there was a significant relationship between LGR-5 levels and clinical stage according to TNM at KKR $(p=0.001)$. This can be seen from the percentage of samples from the examination, which shows that LGR-5 levels continue to increase along with increasing clinical stages according to TNM, this illustrates that the higher the stage, the LGR-5 levels also increase.

Most cancers are heterogeneous and have different functions and phenotypes at the level of the cell population. Many studies have shown that tumors are a small population of cells that are responsible for tumor onset, development, and recurrence. These are called SPKs (cancer stem cells) (Wang et al., 2013). SPC SPC is the ability of self-renewal and differentiation or tumor initiation. Many signal pathways such as WNT / $\beta$-catenin and notch, such as elephant signal, include pathways involved in the self-renewal behavior of cns to prevent mediation of radiotherapy and chemotherapy. Stem cells from colon cells are the origin of mature stomach cells. TRC cells are thought to originate from basement stem cells that carry a range of epigenetic and genetic mutations (McCubrey et al., 2010).

Further analysis of the microadenoma described that cells expressing LGR-5 were mixed with Paneth cells which are stem cells in the gut crypt. This suggests that a microenvironment such as a normal intestinal crypt is required at this stage of intestinal tumorigenesis (Schepers et al., 2012). In addition, a simulated adenomacarcinoma model has been reported using intestinal organ cell cultures (Matano et al., 2015). Colorectal cancer stem cell levels/expressions indicate that colorectal cancer stem cell stemness levels may have implications for the ability of TRC stem cells to produce more heterogeneous and higher progeny. and this relates to the overall survivor. Ongoing examinations have shown that CRC immature microorganisms are engaged with irregular tissue upliftment and cancer-causing agents in CRC. CRC foundational microorganism levels/articulations assume a significant part in cancer development as far as provocative dysplasiacarcinoma grouping (Kazama et al., 2018).

\section{Degree of differentiation}

The degree of colorectal carcinoma (CRC) can be divided into three, namely well-differentiated, moderately differentiated, and poorly differentiated with various glandular formations (Fadaka et al., 2019). Histopathological grading also showed a statistical relationship to LGR-5 levels. Where the number of samples was found to be the lowest in the well-differentiated histopathological grading group, where only $1.6 \%$ was found, then it increased to $77.0 \%$ in moderated differentiated (moderate differentiation) and increased in poorly differentiated (poor differentiation) by $21,3 \%$. With a value of $\mathrm{p}=0.048(\mathrm{P}<0.05)$ (table 15). This is in line with the study reported by Ihemelandu et al (2019), where the levels of LGR-5 increased with the increase in histopathological grading.

The study by Ihemelandu et al. (2019), also reported that most patients were moderately differentiated (71.1\%), but the least were well-differentiated (33.3\%) (Ihemelandu et al., 2019). Fadaka et al. (2019), reported that around $10 \%$ of diagnosed CRCs were well-differentiated, $70 \%$ were moderately differentiated, and $20 \%$ were poorly differentiated. As for gland formation, it is found in $95 \%$ well-differentiated, 50-95\% moderately differentiated, and $<70 \%$ poorly differentiated (Fadaka et al., 2019). The results of this study are not in line with those reported by Shekarriz et al. (2019), namely their research found that the majority of patients were well-differentiated (90\%) (Shekarriz et al., 2019). Classification of tumor differentiation needs 
to be considered as a factor that correlates with TAM function. Previous studies of colon cancer have shown that a histologically malignant phenotype is associated with macrophage infiltration, disorganized matrix deposits, and extensive stromal reactions.

\section{Metastasis}

In this study, more patients had metastases than those without metastases (55.7\% vs. $44.3 \%)$. Ihemelandu et al. (2019), in their study also reported the same thing, namely that more patients had metastases (55\%). (Ihemelandu et al., 2019). It was found that there were more colorectal cancer (CRC) patients in this study which showed high Leucine-Rich, repeat-containing, G-Protein-Coupled Receptor 5 (LGR-5) levels compared to low $(57.4 \%$ vs $42.6 \%)$. This result is in line with the study report of Ihemelandu et al. (2019), which showed that there were more CRC sufferers with high LGR-5 levels (58.3\% vs. 41.7\%) (Ihemelandu et al., 2019). Inflammatory effects have a role in increasing levels/expression of TRC Cancer Stem Cell markers. TAM and its role in tumor invasion and metastasis have been discussed in several papers. In general, copper is most commonly found in and around tumors. Active tumor cells can reveal a variety of factors that affect the behavior of other tumor stroma cells. The main phenotype was identified because macrophages had ecofriendly capabilities (Baena \& Salinas, 2015).

When comparing the results of different tumor types, many significant differences were found. Although macrophages can kill tumor cells under certain conditions, macrophages can act as tumor promoters by hiding various factors that promote invasion and metastasis. The effect of TAM (Tumor Associated Macrophages) on the prognosis of different tumors depends on the factors of stimulation in two opposite directions of the tumor environment (Zhang et al., 2012). Macrophages are seen to be prominent in various malignant stromal bogies. These cells respond to stimuli from other parts of the tumor by releasing developmental factors, cytokines, chemokines, and enzymes that regulate tumor growth, angiogenesis, invasion, and metastasis. TAM operates in a variety of small environments, including invasive areas, where TAM stimulates cancer cell motility, stromal, and perivascular areas where TAM stimulates metastasis; And avecular and parenchymal regions, where hypoxic tam stimulate angiogenesis (Lewis et al., 2016). Inflammation theory converts macrophages from M1 to M2 so that they can release various growth factors and IL6 cytokines have an activity that can increase the stemness of TRC cancer stem cells. Tam tumors play a central role in the modulation of the micro-environment and the maintenance of cancer stem cell niches in many forms (Ragi et al., 2016). M2 macrophages also play a role in stromal remodeling, immune escape, cancer progression, and metastasis (Biswas et al., 2013).

\section{LGR-5. levels}

Lucin-rich rehashing G-protein-consolidated receptor 5 (LGR-5) is an individual from seven groups of transmembrane GPR recognized lately. LGR-5 is the downstream objective quality of the WNT/ $\beta$-Catanin flagging course and assumes a significant part in fetal turn of events and organogenesis. As of late, a few investigations have shown that LGR-5 is a marker for small digestive tract and stomach undifferentiated organisms (Barker et al., 2007), and notwithstanding glut in CRC patients has uncovered colorectal carcinogenma (CRC) cell-like foundational microorganisms (Zheng et al., 2018). LGR-5 spreads through the TRC network and among the majority of TRC victims (Ihemelandu et al., 2019).

In this study, there was no significant relationship between increased levels of Leucine-rich repeatcontaining G-protein-coupled receptor 5 (LGR-5) and clinicopathological variables such as age ( $\mathrm{p}=0.629$ ), gender $(\mathrm{p}=0.916)$, tumor location. $(\mathrm{p}=0.074)$. These results are in line with the study report by Zheng et al. (2018), namely that increased levels of LGR-5 were not significantly associated with patient age, gender, tumor size, tumor location, tumor differentiation, and lymphovascular invasion (P > 0.05) (Zheng et al., 2018).

Likewise, with the study report by Ihemelandu et al. (2019), no significant relationship was found between high versus low LGR-5 levels for gender and age (Ihemelandu et al., 2019). Kim et al also explained that there was no statistically significant difference in the relationship between LGR-5 levels and clinicopathological factors. Vascular invasion, lymph node metastasis, and tumor stage are associated with increased levels of Leucine-rich repeat-containing G-protein-coupled receptor 5 (LGR-5) (Shekarriz et al., 2019).

Arungpadang, M. P., Lusikooy, R. E., Kasim, F., Mappincara, M., \& Warsinggih, W. (2021). Correlation between levels of LGR-5 (leucine rich repeat containing protein coupled receptor 5) with clinical aspects and colorectal carcinoma stage. International Journal of Health Sciences, 5(3), 331-343. https://doi.org/10.53730/ijhs.v5n3.1541 
Therefore, LGR-5 as a cancer stem cell may be involved in the pathogenesis, development, and metastasis of colorectal cancer (CRC) (Zheng et al., 2018). In addition, patients with low LGR-5 levels have a higher survival rate. Various studies have been carried out to determine the role of cancer stem cells in drug resistance. The permanent ability of cancer stem cells to repair damaged genomes and self-renewal properties are also responsible for the development of resistance to chemo-radiotherapy. Excess LGR-5 levels are not only associated with chemoresistance but also with metastasis and cancer stage (Shekarriz et al., 2019).

\section{LGR-5 correlation with clinicopathology of colorectal cancer patients}

Based on the results of this study, it appears that lgr-5 levels for tumor stage are related/correlation, degree of differentiation and metastas e.g. P-value is $<0.05$. Meanwhile, there was no correlation between gender, age, and tumor location as P-value was $>0.05$. Correlation coefficient to assess the relation/correlation of lgr-5 level for tumor stage, the degree of discrimination and incidence of metastas enumerated using Pearson test. From the data analysis of this study, it was found that the correlation was very strong $(R=0.799)$. The above results are in line with those reported by Zheng et al. (2018), that LGR-5 levels were significantly associated with the depth of tumor invasion, lymph node metastasis, tumor stage, and perineural invasion $(\mathrm{P}<0.01)$. LGR-5 levels significantly play a role in cancer development (Zheng et al., 2018).

Further, LGR-5 was observed more often than the results of the study conducted by Wu et Al in Advanced Colorectal Cancer (CRC) that LGR-5 positive levels were found in stage III cancer tissue and 100\% (10/10) stage IV cancer tissue at 83.1\% (54/65) (Wu et al., 2012). The high level of LGR-5 was very much linked to the depth of attack, lymph node metastasis $(\mathrm{P}=0.001)$, and remote metastasis $(\mathrm{P}=0.004)$. Furthermore, $\lg -5$ levels gradually increased with an increase in the tumor phase $(\mathrm{P}=0.001)$. These results show that high levels of LGR-5 receptor levels usually correlate with more malignant and metastatic tumors. These results suggest that LGR-5 may play an important role in tumor development (Wu et al., 2012).

Several meta-analyses have also reviewed the correlation of LGR-5 levels with colorectal cancer. The metaanalysis conducted by Jiang et al. evaluated the effect of LGR-5 levels on the survival of colorectal cancer patients in 12 studies consisting of 2,600 patients. Excess LGR-5 levels were significantly associated with deep invasion $(\mathrm{P}=0.002)$, lymph node metastasis $(\mathrm{P}=0.003)$, distant metastasis $(\mathrm{P}=0.001)$, and AJCC stage $(\mathrm{P}=$ $0.01)$; but not correlated with tumor grading $(P=0.433)$ (Jiang et al., 2016). Several variables in other studies also showed a positive correlation of LGR-5 levels, such as that of Gzil et al., who showed lower LGR-5 levels were significantly correlated with the presence of lymph node metastases $(p=0.011)$, while LGR levels The high -5 was statistically significant in vascular invasion ( $p=0.027$ ) (Gzil et al., 2020).

No important association was shown by Kim et al, who assessed the level of LGR-5 with colorectal cancer. They used immunohistochemical techniques to test lgr-5 levels with retrospective effect in paraffin-embedded samples from 337 patients with colorectal cancer (CRC) between January 2009-December 2013. Then the correlation between the level of patients and the therapeutic data and clinical results was analyzed. The results showed that the low and high LGR-5 levels in 337 patients were 175 (51.9\%) and 162 (48.1\%). There was no statistically significant difference in the cooperation of LGR-5 levels with clinically pathological factors (age, tumor location, lynca, vascular, and perinural invasion, TNM phase, and histopathological discrimination).

Many investigations have shown that over the top levels of the LGR-5 protein in CRC are related to cancer inception, protection from 5-FU-based chemotherapy, and repeat. Thusly, LGR-5 levels are viewed as a potential biomarker related to helpless visualization in CRC. In any case, a new review study comprising of 891 colorectal adenocarcinomas uncovered that LGR-5 has no prognostic importance in CRC (Jiang et al., 2016). The limitations of this study are taken only from a center or hospital so that it does not describe the level of Lycen-rich G-protein-coupled receptor 5 (LGR-5) in colorectal cancer patients in a region. In addition, there was no long-term follow-up. For this reason, further research is needed with larger sample size and more hospital centers (Vitola et al., 1996; Öhman, 1982). 


\section{Conclusion}

Based on the description of the problem and data analysis that has been described in the previous chapters, several conclusions can be drawn, namely as follows:

a) Of the 61 patients, there were 35 patients with high LGR-5 levels and 26 patients with low LGR- 5 levels.

b) There was no significant relationship between LGR-5 levels on gender, age, and tumor location of patients with colorectal cancer.

c) There is a significant relationship between LGR-5 levels on cancer stage, degree of differentiation, and incidence of metastases in colorectal cancer patients

d) Based on the Pearson correlation, there is a relationship between LGR-5 levels and cancer stage, the degree of differentiation and metastasis of colorectal cancer patients is a very strong relationship $(\mathrm{R}=0.799)$.

Acknowledgments

We are grateful to two anonymous reviewers for their valuable comments on the earlier version of this paper.

Arungpadang, M. P., Lusikooy, R. E., Kasim, F., Mappincara, M., \& Warsinggih, W. (2021). Correlation between levels of LGR-5 (leucine rich repeat containing protein coupled receptor 5) with clinical aspects and colorectal carcinoma stage. International Journal of Health Sciences, 5(3), 331-343. https://doi.org/10.53730/ijhs.v5n3.1541 


\section{References}

Amori, N., Aghajani, M., Asgarian, F. S., \& Jazayeri, M. (2017). Epidemiology and trend of common cancers in Iran (2004-2008). European journal of cancer care, 26(5), e12449.

Baena, R., \& Salinas, P. (2015). Diet and colorectal cancer. Maturitas, 80(3), 258-264.

Barker, N., \& Clevers, H. (2010). Leucine-rich repeat-containing G-protein-coupled receptors as markers of adult stem cells. Gastroenterology, 138(5), 1681-1696. https://doi.org/10.1053/j.gastro.2010.03.002

Barker, N., Van Es, J. H., Kuipers, J., Kujala, P., Van Den Born, M., Cozijnsen, M., ... \& Clevers, H. (2007). Identification of stem cells in small intestine and colon by marker gene Lgr5. Nature, 449(7165), 10031007.

Beckmann, K. R., Bennett, A., Young, G. P., Cole, S. R., Joshi, R., Adams, J., ... \& Roder, D. (2015). Sociodemographic disparities in survival from colorectal cancer in South Australia: a population-wide data linkage study. BMC health services research, 16(1), 1-14.

Biswas, S. K., Allavena, P., \& Mantovani, A. (2013, September). Tumor-associated macrophages: functional diversity, clinical significance, and open questions. In Seminars in immunopathology (Vol. 35, No. 5, pp. 585-600). Springer Berlin Heidelberg.

Bollati, V., \& Baccarelli, A. (2010). Environmental epigenetics. Heredity, 105(1), 105-112.

Bratt, O. (2002). Hereditary prostate cancer: clinical aspects. The Journal of urology, 168(3), 906-913. https://doi.org/10.1016/S0022-5347(05)64541-7

Carchi, J. A. Y. ., Catagua, T. C. M. ., Rivera, D. G. B. ., Mera, V. B. ., \& Rosario, M. del . (2021). From beginner to expert, experience of the rotating nursing intern in pre-professional practice. International Journal of Health Sciences, 5(2), 111-117.

Christensen, B. C., Houseman, E. A., Marsit, C. J., Zheng, S., Wrensch, M. R., Wiemels, J. L., ... \& Kelsey, K. T. (2009). Aging and environmental exposures alter tissue-specific DNA methylation dependent upon CpG island context. PLoS genetics, 5(8), e1000602.

Dharmayuda, T. G., Suega, K., Bakta, I. M., \& Sumohadi, I. M. D. (2021). Ki67 expression and prognostic aspects of colorectal cancer. International Journal of Health Sciences, 5(2), 79-88.

Fadaka, A. O., Pretorius, A., \& Klein, A. (2019). Biomarkers for stratification in colorectal cancer: microRNAs. Cancer Control, 26(1), 1073274819862784.

Fatemi, S. R., Pourhoseingholi, M. A., Asadi, F., Vahedi, M., Pasha, S., Alizadeh, L., \& Zali, M. R. (2015). Recurrence and five-year survival in colorectal cancer patients after surgery. Iranian journal of cancer prevention, 8(4).

Fukuma, M., Tanese, K., Effendi, K., Yamazaki, K., Masugi, Y., Suda, M., \& Sakamoto, M. (2013). Leucine-rich repeat-containing G protein-coupled receptor 5 regulates epithelial cell phenotype and survival of hepatocellular carcinoma cells. Experimental cell research,319(3), 113-121. https://doi.org/10.1016/j.yexcr.2012.10.011

Globocan 2018. (2018). World Health Organization. Global Health Observatory.

Gzil, A., Zarębska, I., Jaworski, D., Antosik, P., Durślewicz, J., Maciejewska, J., ... \& Szylberg, Ł. (2020). The prognostic value of leucine-rich repeat-containing G-protein (Lgr5) and its impact on clinicopathological features of colorectal cancer. Journal of Cancer Research and Clinical Oncology, 146(10), 2547-2557.

Heinen, C. D. (2010). Genotype to phenotype: analyzing the effects of inherited mutations in colorectal cancer families. Mutation Research/Fundamental and Molecular Mechanisms of Mutagenesis, 693(1-2), 32-45. https://doi.org/10.1016/j.mrfmmm.2009.09.004

Huang, T., Qiu, X., Xiao, J., Wang, Q., Wang, Y., Zhang, Y., \& Bai, D. (2016). The prognostic role of Leucine-rich repeat-containing G-protein-coupled receptor 5 in gastric cancer: A systematic review with metaanalysis. Clinics and research in hepatology and gastroenterology, 40(2), 246-253. https://doi.org/10.1016/j.clinre.2015.07.009

Ihemelandu, C., Naeem, A., Parasido, E., Berry, D., Chaldekas, K., Harris, B. T., ... \& Albanese, C. (2019). Clinicopathologic and prognostic significance of LGR5, a cancer stem cell marker in patients with colorectal cancer. Colorectal cancer, 8(4), CRC11.

Jiang, Y., Li, W., He, X., Zhang, H., Jiang, F., \& Chen, Z. (2016). Lgr5 expression is a valuable prognostic factor for colorectal cancer: evidence from a meta-analysis. BMC cancer, 16(1), 1-9. 
Kazama, S., Kishikawa, J., Kiyomatsu, T., Kawai, K., Nozawa, H., Ishihara, S., \& Watanabe, T. (2018). Expression of the stem cell marker CD133 is related to tumor development in colorectal carcinogenesis. Asian journal of surgery, 41(3), 274-278.

KJ, W. (1977). New Hope For Breastcancer Patients. InPharma, 7.

Kuipers, E. J., Grady, W. M., Lieberman, D., Seufferlein, T., Sung, J. J., \& Boelens, P. G. (2015). Nat Rev Dis Primers. V1, DOI, 10.

Leushacke, M., \& Barker, N. (2012). Lgr5 and Lgr6 as markers to study adult stem cell roles in self-renewal and cancer. Oncogene, 31(25), 3009-3022.

Lewis, C. E., Harney, A. S., \& Pollard, J. W. (2016). The multifaceted role of perivascular macrophages in tumors. Cancer cell, 30(1), 18-25.

Matano, M., Date, S., Shimokawa, M., Takano, A., Fujii, M., Ohta, Y., ... \& Sato, T. (2015). Modeling colorectal cancer using CRISPR-Cas9-mediated engineering of human intestinal organoids. Nature medicine, 21(3), 256-262.

McCubrey, J. A., Abrams, S. L., Stadelman, K., Chappell, W. H., LaHair, M., Franklin, R. F., \& Steelman, L. S. (2010). Targeting signal transduction pathways to eliminate chemotherapeutic drug resistance and cancer stem cells. Advances in enzyme regulation, 50(1), 285.

Nakata, S., Phillips, E., \& Goidts, V. (2014). Emerging role for leucine-rich repeat-containing G-protein-coupled receptors LGR5 and LGR4 in cancer stem cells. Cancer management and research, 6, 171.

Notoatmodjo, S. (2010). Ilmu perilaku kesehatan.

Öhman, U. (1982). Prognosis in patients with obstructing colorectal carcinoma. The American journal of surgery, 143(6), 742-747. https://doi.org/10.1016/0002-9610(82)90050-2

Raggi, C., Mousa, H. S., Correnti, M., Sica, A., \& Invernizzi, P. (2016). Cancer stem cells and tumor-associated macrophages: a roadmap for multitargeting strategies. Oncogene, 35(6), 671-682.

Rawla, P., Sunkara, T., \& Barsouk, A. (2018). Epidemiology of colorectal cancer: incidence, mortality, survival, and risk factors. Prz Gastroenterol. 2019; 14 (2): 89-103.

Rhee, Y. Y., Kim, K. J., \& Kang, G. H. (2017). CpG island methylator phenotype-high colorectal cancers and their prognostic implications and relationships with the serrated neoplasia pathway. Gut and liver, 11(1), 38.

Schepers, A. G., Snippert, H. J., Stange, D. E., van den Born, M., van Es, J. H., van de Wetering, M., \& Clevers, H. (2012). Lineage tracing reveals Lgr5+ stem cell activity in mouse intestinal adenomas. Science, 337(6095), 730-735.

Shekarriz, R., Montazer, F., \& Alizadeh-Navaei, R. (2019). Overexpression of cancer stem cell marker Lgr5 in colorectal cancer patients and association with clinicopathological findings. Caspian journal of internal medicine, 10(4), 412.

Siegel, R. L., Miller, K. D., Goding Sauer, A., Fedewa, S. A., Butterly, L. F., Anderson, J. C., ... \& Jemal, A. (2020). Colorectal cancer statistics, 2020. CA: a cancer journal for clinicians, 70(3), 145-164.

Thoresen, L., Frykholm, G., Lydersen, S., Ulveland, H., Baracos, V., Prado, C. M., ... \& Falkmer, U. (2013). Nutritional status, cachexia and survival in patients with advanced colorectal carcinoma. Different assessment criteria for nutritional status provide unequal results. Clinical nutrition, 32(1), 65-72. https://doi.org/10.1016/j.clnu.2012.05.009

Valastyan, S., \& Weinberg, R. A. (2011). Tumor metastasis: molecular insights and evolving paradigms. Cell, 147(2), 275-292. https://doi.org/10.1016/j.cell.2011.09.024

Vitola, J. V., Delbeke, D., Sandler, M. P., Campbell, M. G., Powers, T. A., Wright, J. K., ... \& Pinson, C. W. (1996). Positron emission tomography to stage suspected metastatic colorectal carcinoma to the liver. The American journal of surgery, 171(1), 21-26. https://doi.org/10.1016/S0002-9610(99)80067-1

Wang, H., Chen, Y., Fernandez-Del Castillo, C., Yilmaz, O., \& Deshpande, V. (2013). Heterogeneity in signaling pathways of gastroenteropancreatic neuroendocrine tumors: a critical look at notch signaling pathway. Modern Pathology, 26(1), 139-147.

Widana, I.K., Sumetri, N.W., Sutapa, I.K., Suryasa, W. (2021). Anthropometric measures for better cardiovascular and musculoskeletal health. Computer Applications in Engineering Education, 29(3), 550561. https://doi.org/10.1002/cae.22202

Winawer, S. J. (1999). Natural history of colorectal cancer. The American journal of medicine, 106(1), 3-6. https://doi.org/10.1016/S0002-9343(98)00338-6

Arungpadang, M. P., Lusikooy, R. E., Kasim, F., Mappincara, M., \& Warsinggih, W. (2021). Correlation between levels of LGR-5 (leucine rich repeat containing protein coupled receptor 5) with clinical aspects and colorectal carcinoma stage. International Journal of Health Sciences, 5(3), 331-343. https://doi.org/10.53730/ijhs.v5n3.1541 
Wu, X. S., Xi, H. Q., \& Chen, L. (2012). Lgr5 is a potential marker of colorectal carcinoma stem cells that correlates with patient survival. World journal of surgical oncology, 10(1), 1-8.

Yuan, J., Yu, J. X., \& Ge, J. (2010). Sexual dimorphism on the neurogenic potential of rhesus monkeys mesenchymal stem cells. Biochemical and biophysical research communications, 396(2), 394-400.

Zhang, Q. W., Liu, L., Gong, C. Y., Shi, H. S., Zeng, Y. H., Wang, X. Z., ... \& Wei, Y. Q. (2012). Prognostic significance of tumor-associated macrophages in solid tumor: a meta-analysis of the literature. PloS one, 7(12), e50946.

Zheng, Z., Yu, H., Huang, Q., Wu, H., Fu, Y., Shi, J., ... \& Fan, X. (2018). Heterogeneous expression of Lgr5 as a risk factor for focal invasion and distant metastasis of colorectal carcinoma. Oncotarget, 9(53), 30025.

Ziskin, J. L., Dunlap, D., Yaylaoglu, M., Fodor, I. K., Forrest, W. F., Patel, R., ... \& Jubb, A. M. (2013). In situ validation of an intestinal stem cell signature in colorectal cancer. Gut, 62(7), 1012-1023. 


\section{Biography of Authors}

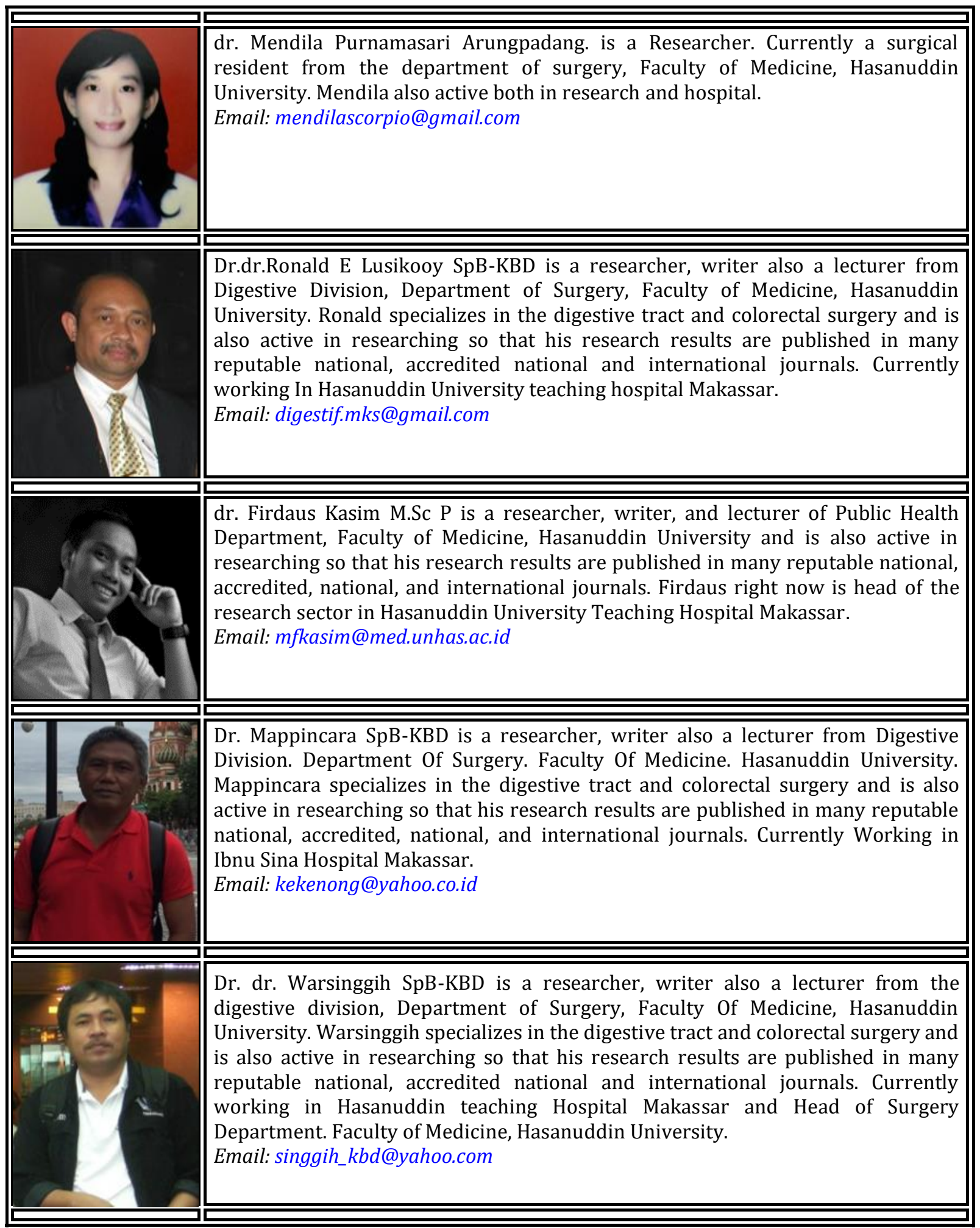

Arungpadang, M. P., Lusikooy, R. E., Kasim, F., Mappincara, M., \& Warsinggih, W. (2021). Correlation between levels of LGR-5 (leucine rich repeat containing protein coupled receptor 5) with clinical aspects and colorectal carcinoma stage. International Journal of Health Sciences, 5(3), 331-343. https://doi.org/10.53730/ijhs.v5n3.1541 